\title{
VISUAL-SPATIAL ATTENTION IN DEVELOPMENTAL DYSLEXIA
}

\author{
Andrea Facoetti ${ }^{1,2}$, Pierluigi Paganoni ${ }^{3}$, Massimo Turatto ${ }^{2}$, Valentina Marzola $^{2}$ and \\ Gian Gastone Mascetti ${ }^{2}$ \\ ( ${ }^{1}$ Unit of Cognitive Neuropsychology, Scientific Institute "Eugenio Medea", Lecco, Italy; \\ ${ }^{2}$ Department of General Psychology, University of Padova, Italy; ${ }^{3}$ UONPI Bergamo \\ General Hospital, Italy)
}

\begin{abstract}
Orienting and focusing of visual attention are two processes strictly involved in reading. They were studied in a group of dyslexic children and normal readers. Shifting of attention by both peripheral and central visual cues was studied by means of the covert orienting paradigm. Focusing, consisting in the ability to control the size of the attentional focus, was investigated using simple reaction times in central vision. Results showed that dyslexics had a specific disability in the shifting of attention caused by a peripheral cue at short SOAs, and were also able to maintain attention focused for short periods of time only, presumably not long enough for efficient visual processing. Our results support the suggestion that visual selective attention deficits in disabled readers may be due to a specific difficulty in orienting and focusing.
\end{abstract}

Key words: dyslexia, specific reading disorder, spatial attention, focusing, orienting, reaction time

\section{INTRODUCTION}

Developmental dyslexia has been defined as "a disorder manifested by a difficulty in learning to read despite conventional instruction, adequate intelligence and social-cultural opportunity. It is dependent upon fundamental cognitive disabilities which are frequently of constitutional origin" (World Federation of Neurology). More recently, the terms dyslexia and specific reading disability (SRD) have been used interchangeably to describe the condition of healthy, well-adjusted children who show normal progress in school subjects but who are at least 2 years behind in reading (World Heath Organization, ICD-10, 1996).

Four etiological causes for dyslexia have been suggested: perceptual deficits (e.g., Hinshelwood, 1917; Orton, 1937), memory deficits (e.g., Liberman, Mann and Shankweiler, 1982; Jorn, 1983), language processing deficits (e.g., Rozin and Gleitman, 1977; Marsh, Freidman and Welsh, 1981), and visual processing deficits (e.g., Lovegrove, Martin and Slaghuis, 1982; Livingstone, Rosen, Drislane et al., 1991).

However, specific attentional deficits may account for dyslexia too, with some studies reporting some kind of visual attention impairments in dyslexic children (Ackerman, Dykman and Gardner, 1990; August and Garfinkel, 1990). 
Recently, Casco, Tressoldi and Dellantonio (1998) found that children with the lowest performances in searching a target letter in a set of background letters showed both a significantly slower reading rate and a higher number of visual errors in comparison with children who exhibited higher performances in the visual search task. The authors pointed out that this difference could be due to a deficit of selective visual attention. In line with this interpretation, other studies have indicated that the ability to perform a visual search task is reduced in poor readers and in dyslexics (Williams, Brannan and Latirgue, 1987; Ruddock, 1991; Casco and Prunetti, 1996). Also, a recent study by Sharma, Halperin, Newcorn et al. (1991) reported a deficit of focused attention in a group of children with learning disabilities. Finally, results of a study of Williams and Bologna (1985) indicated a negative correlation between the effects of perceptual grouping and reading ability: grouping effects were stronger in poor readers. The authors suggested that poor readers relied heavily on the holistic information they acquired during reading before a more detailed analysis was accomplished by the focal attentional mechanism.

Reading is a complex activity involving a number of distinct visually mediated responses, during which a series of short-latency ocular movements, called saccades, are performed. The main function of saccades is to bring a new region of the text into central vision. In addition, saccades are separated by brief fixations during which a detailed visual processing is carried out.

Many studies suggest that orienting of attention might play a causal role in the generation of saccades (Sheperd, Findlay and Hockey, 1986; Johnson, 1994; Inhoff, Pollatsek, Posner et al., 1989). Consequently, it seems reasonable to assume that there might be a relationship between the dysfunction of the oculomotor system and the attentional deficits that may both be found in dyslexic children (Morris and Rayner, 1991).

Also, several studies have pointed out that dyslexics have difficulty suppressing the information coming from the periphery of the visual field, which would interfere with the process of foveal reading (Geiger and Lettvin, 1987; Geiger, Lettvin and Fahle, 1994; Rayner, Murphy, Henderson et al., 1989). This results could be due to a specific deficit of inhibiting stimuli outside the focus of attention (Morris and Rayner, 1991).

Therefore, the aim of the present study was to investigate both orienting and focusing of visual attention in dyslexic children. Indeed, there are evidence suggesting that focusing, which basically consists in adjusting the width of the attentional focus to the size of the observed object, is independent of orienting (Benso, Turatto, Mascetti et al., 1998; Castiello and Umiltà, 1990; Stoffer and Umiltà, 1997; Turatto, Benso, Facoetti et al., 1999). The latter consists in moving the focus across the visual field, and was assessed by means of a covert paradigm (Posner, 1980), which presupposes shifting of attention in the visual field without any eye movements (Posner, Snyder and Davidson, 1980). The basic experiment devised by Posner and his colleagues consists of detecting (by pressing as quickly as possible a key) a white spot appearing on the computer screen. Subjects also kept their eyes fixed in the center of the screen, in order to avoid a confounding factor due to visual acuity. Prior to the appearance of the target, however, a cue was presented to attract attention to one of the two 
locations (to the left or right of fixation). Three types of cue were presented: valid, when the cue indicated the correct target location, invalid, when the cue attracted subject's attention to the opposite visual field, or neutral, when the cue provided no spatial information about target position. The results of such experiment were quicker reaction times (RTs) for valid cues, slower RTs for invalid cues, and intermediate RTs for neutral cues (Posner, 1980). Subsequently, Posner suggested that orienting of attention toward a target may be considered in terms of three more elementary mental operations: disengaging attention from the current position, functionally linked to mechanisms in the parietal lobe (Posner, Walker, Friedrich et al.,1984); moving of attention to the target location, which requires midbrain mechanisms (Posner, Cohen and Rafal, 1982); and engaging the focus of attention to the new target position, which requires mechanisms in the thalamic areas (Rafal and Posner, 1987).

In the present study two different types of cues were used: peripheral cues, consisting in a peripheral abrupt visual onset which is assumed to exogenously draw attention to its position without taxing cognitive processes (Jonides, 1981; Posner, Cohen, Choate et al., 1984), and central cues, which are able to direct attention to a given position only endogenously, that is by means of an act of will by the subject. Central cues require more controlled cognitive processing and may be impaired when a subject is engaged in other cognitively demanding tasks, such as actively carrying a memory load (Jonides, 1981; Posner et al., 1984). There is also evidence that the two orienting mechanisms rely on different neuroanatomical structures: the exogenous mechanism seems to be controlled by the parietal lobe, whereas the voluntary mechanism seems to be controlled by the frontal lobe (Posner and Petersen, 1990). Some researchers have argued that the most important factor for distinguishing between an automatic and a voluntary allocation of attention is the stimulus onset asynchrony (SOA), that is, the interval between cue and target-stimulus. For instance, by setting a SOA at 100 or $150 \mathrm{~ms}$, and using a peripheral cue, orienting would be automatic and would occur without volitional control, whereas at longer SOAs (e.g., $800 \mathrm{~ms}$ ) a greater voluntary control on orienting would be required to maintain attention on the cued position (Epstein, Conners, Erhardt et al., 1997). Yet another important feature determining automatic or voluntary orienting seems to be set-validity, that is, the ratio between valid and invalid trials (Rosen, Rao, Caffarra et al., 1999). Automatic orienting is supposed to occur regardless of the validity of the cue, that is even when the cue is misleading. Therefore, an exogenous shift of attention is thought to be correctly investigated when subjects have no incentive to move their attention toward the cue. Thus, although in the present study we used informative cues (80\% validity), we assume that the issue of automatic orienting was nevertheless addressed because of the use of peripheral abrupt onset cues at short SOAs (about $150 \mathrm{~ms}$ ).

In relation to focusing of attention, control of the focus width was assessed by presenting a target-stimulus inside different cue sizes. For focusing is intended to be the process by means of which the width of the spatial attention resource is adapted to the size of a given object. It has already been demonstrated that there is an inverse relationship between target detection RTs 
and cue size (Benso et al., 1988; Castiello and Umiltà, 1990; Egeth, 1977; Eriksen and St. James, 1986; Turatto et al., 1999). Typically, because attentional resources would be more concentrated in a narrow area than in a wide one, the smaller the focus the higher the speed of processing within its borders. This is what is called the cue-size effect.

In all the experiments presented in this study both orienting and focusing were investigated using a simple detection task. Even though a simple RT task is sometimes considered less informative than a paradigm based on stimulus discrimination, that is on a choice reaction task, in our opinion, the choice of the experimental paradigm should depend on what aspect of attention is being investigated. If what is being looked at is only the selection of a spatial position, a simple detection task is perfectly suitable for studying both orienting (e.g., Posner et al., 1980) and focusing of attention (e.g., Benso et al., 1998; Castiello and Umiltà, 1990). In addition, a simple detection task allows the investigation of the simple allocation of spatial attention involved in orienting and focusing, excluding other attentional factors such as "expectation" and "intention", which would be otherwise present in a choice reaction task (Van der Heijden, 1992).

Orienting of attention was investigated in Experiments 1 and 2 which were counterbalanced across subjects: half of the subjects performed Experiment 1 first and then Experiment 2, whereas the sequence was reversed for the remaining subjects.

\section{EXPERIMENT 1}

The aim of the present experiment was to address automatic orienting of attention in dyslexic children, normally reading children and adult subjects. Therefore, the cue consisted in an abrupt onset in the periphery of the visual field, followed by the target after a brief SOA. As discussed earlier, these experimental conditions are thought to elicit an exogenous shift of attention (Epstein et al., 1997; Pearson et al., 1995), even though this paradigm cannot be considered as "purely automatic" because the cue had a $80 \%$ validity. However, because our aim was to address possible deficits in dyslexic children when attention is triggered by peripheral onset stimuli, our experimental conditions seem to meet the criterion for correct evaluation.

In addition, whereas Brannan and Williams (1987) studied automatic orienting of poor and good readers using accuracy as dependent variable and letters as stimuli, the present experiment relied on a simple RT task, consisting in the detection of a white dot presented peripherally.

Materials and Methods

\section{Subjects}

Subjects were 10 adults and 20 children with normal or corrected vision.

Adults (5 males and 5 females, mean age 30), were workers at the Neuropsychiatry Department of Bergamo.

Ten children, 7 males and 3 females (mean age 10 years), were classified as dyslexic because they scored 2 SD below the normal level at the MT reading test (Cornoldi and 
Colpo, 1981). None had any known neurological or sensory impairment, emotional disturbance, or were taking medication.

The remaining ten children, 7 males and 3 females (mean age 9.4 years), were normal readers. Children of both groups were matched for age and IQ (Wechsler, 1986).

\section{Apparatus and Procedure}

Tests were carried out in a dimly lit room. Subjects sat in front of a monitor screen (15 inch and with a luminance $0.5 \mathrm{~cd} / \mathrm{m}^{2}$ ), with their head positioned on a headrest so that the eyes-screen distance was $40 \mathrm{~cm}$. The fixation point consisted of a cross $\left(1.4^{\circ}\right.$ of visual angle) appearing in the center of the screen. Two circles $\left(3^{\circ}\right)$ were presented at $10^{\circ}$ of eccentricity at both sides of the fixation point simultaneously. A vertical arrow $\left(1.5^{\circ}\right)$ appearing above the circles was used as cue. A dot $\left(0.5^{\circ}\right)$ appearing in the center of one of the two circles was used as target. Stimuli were white and had a luminance of $24 \mathrm{~cd} / \mathrm{m} 2$. Subjects were instructed to keep their eyes fixed on the cross throughout the duration of the trial. However, eye movements were monitored by means of a system composed of infrared-ray spectacles connected with an amplifier, an analog-digital converter and a computer. Any eye movement larger than $1^{\circ}$ was detected by the system and the corresponding trial was discarded but not replaced.

Each trial started with the onset of the fixation point accompanied by a $1000-\mathrm{Hz}$ warning signal tone. After $504 \mathrm{~ms}$, the two circles were displayed, and again after $504 \mathrm{~ms}$ the cue was shown for $99 \mathrm{~ms}$. Afterwards, the target appeared for $99 \mathrm{~ms}$ inside one of the circles. Two different SOAs were used: 136 and $238 \mathrm{~ms}$, and they were presented randomly. On valid trials the target appeared inside the circle indicated by the cue, whereas on invalid trials the target appeared in the opposite circle of that indicated by the cue. Finally, on neutral trials, both circles were cued (one arrow on each circle) and the target was presented randomly inside only one of the two circles.

Subjects were instructed to react as quickly as possible to the target onset by pressing the spacebar of a computer keyboard, and their RTs were recorded by the computer. The maximum time allowed to respond was $1 \mathrm{sec}$. Catch trials, in which the target was not presented and subjects did not have to respond, were intermingled with normal trials.

The experimental session consisted of 144 trials divided into two blocks of 72 trials each. Trials were distributed as follows: 32 valid trials (16 for each SOA, 8 for each side), 20 neutral trials (10 for each SOA, 5 for each side), 8 invalid trials (4 for each SOA, 2 for each side), and 12 catch trials (about $17 \%$ of the total trials). The cue was valid on $80 \%$ of the trials.

\section{Results}

Mean correct RTs were entered into a four-way repeated measure analysis of variance (ANOVA), in which the three within-subject factors were type of trial (valid, invalid and neutral), SOA (136 and $238 \mathrm{~ms}$ ) and stimulus position (right and left side), and the between-subject factor was group (dyslexic children, normally reading children and adults).

The main effect of group was significant, $\mathrm{F}(2,27)=8.09, \mathrm{p}<0.01$; RTs were faster in adults (357 ms), slower in normal readers (406 ms) and even slower in dyslexics (484 ms). The main effect of type of trial was also significant, $\mathrm{F}(2,54)=15.3, \mathrm{p}<0.001$; RTs were faster on valid trials $(404 \mathrm{~ms})$ and slower on invalid ones (428 ms) as compared with RTs on neutral trials (413 ms). The main effect of SOA was close to significance, $F(1,27)=4.18$, p $=0.051(136-\mathrm{ms} \mathrm{SOA}=422 \mathrm{~ms} ; 238-\mathrm{ms}$ SOA $=408 \mathrm{~ms})$.

The group $\times$ type of trial interaction was significant, $F(4,54)=2.95, p<$ 0.05. Data were further analyzed by Newman-Keuls post-hoc test which 


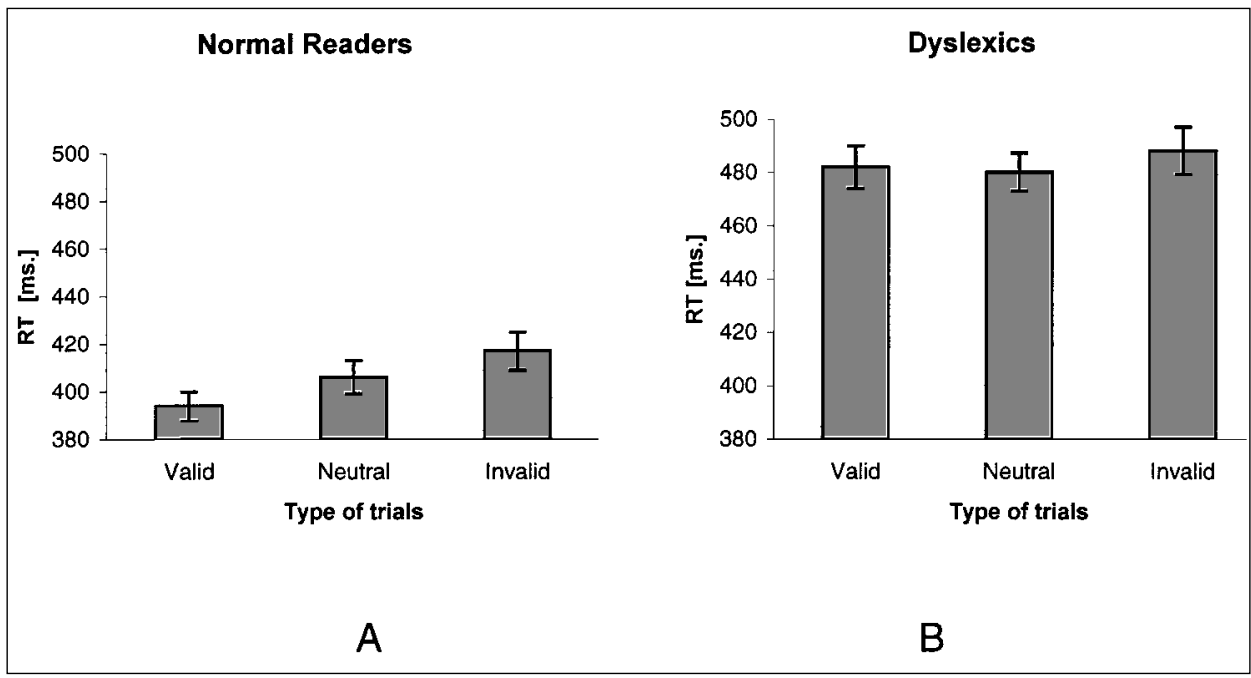

Fig. 1 - Mean reaction time (RT) as a function of validity and group of the periphery cue in Experiment 1 showing a significant effect for normal readers but not for dyslexics.

indicated that the difference between valid and invalid conditions was significant in normal readers $(24 \mathrm{~ms}, \mathrm{p}<.05)$ but not in dyslexics.

Figure 1 shows the effect of validity in normal readers and dyslexics. In normal readers (Figure 1A) RTs were faster on valid trials (benefits) and slower on invalid ones (costs) as compared with neutral trials. By contrast, there were no differences between these conditions in dyslexics (Figure 1B).

\section{Discussion}

Generally, RTs of dyslexics were slower in comparison with those of normal readers and adults. However, the most interesting result was that normally reading children showed both benefits $(12 \mathrm{~ms})$ and costs $(12 \mathrm{~ms})$ when the cue provided correct and incorrect information, respectively. Therefore, it seems that their automatic mechanism of orienting worked properly, and their attention was exogenously drawn by the peripheral onset to the cued position. This finding is in accordance with previous studies by Posner (1980) and Posner et al. (1980). By contrast, dyslexic children showed a deficit in the exogenous allocation of attention, in that a peripheral visual onset did not attract attention, so that neither benefits nor costs were observed.

These findings partially confirm those of Brannan and Williams (1987) who found orienting deficits in poor readers. Their study showed that poor readers unlike controls (good readers and adults) - did not display benefits and costs when the cue correctly and incorrectly predicted the location of the target, respectively. Also, they reported that at the 100-ms SOA (or below), accuracy of poor readers was generally lower than that of controls, whereas the two groups did not differ when SOAs were longer (150 and $170 \mathrm{~ms})$. The authors suggested that poor readers had a deficit of the transient visual system and that were unable to use cue information because they could not detect the temporal 
ordering of cue and target, thus slowing down orienting of attention.

In the present study the deficit of orienting in dyslexics was replicated and thus confirmed by a simple detection task, in which it is safe to assume that high levels of cognitive processing, such as letter identification, were not involved. In addition, dyslexic children were not able to orient attention at the longest SOA (238 ms) too. This finding is not consistent with the hypothesis that the orienting deficit in dyslexics was due to their inability to detect the temporal ordering between the cue and the target. However, it is worth noting that there are some experimental differences between the study of Brannan and Williams (1987) and the present one: first, in the present experiment orienting was evaluated using a white dot as target, while in previous one letters were used. Second, we used RTs as dependent variable, whereas Brannan and Williams (1987) used accuracy.

The deficit in the automatic orienting mechanism might be caused either by an inability to use the cue information in general, or by an inability to use cue information because it was shown in the periphery of the visual field. In other words, is the deficit revealed by Experiment 1 related to peripheral cues only, or is it related to the use of cues in general?

Experiment 2 was performed in an attempt to provide an answer to this question.

\section{EXPERIMENT 2}

Some researchers have stressed that processing of peripheral stimuli in dyslexic children would be impaired by a deficit in their transient visual system (Lovegrove et al., 1982). Transient neurons are particularly concentrated in retinal peripheral areas (Hoffmann, Stone and Sherman, 1972), and they seem to play a crucial role in regulating the orienting mechanism of selective spatial attention (Breitmeyer and Ganz, 1976). Yet, it is still unknown whether the transient deficit of dyslexics is an actual dysfunction of the transient system or whether it is caused by an anomalous delay in the development of cognitive functions, which would hamper manipulation of attentional resources.

Therefore, the purpose of Experiment 2 was to study voluntary orienting of attention in dyslexics, normal readers and adults. In comparison with Experiment 1 , the present study presented two main significant differences. First, cues were displayed on the central part of the visual field. Second, we employed longer SOAs because the voluntary allocation of spatial attention seems to reach its maximal efficiency after about $500 \mathrm{~ms}$ from cue presentation (Muller and Rabbitt, 1989; Warner, Juola and Koshino, 1990).

We assumed that this experimental paradigm might provide some clues about the orienting impairment of dyslexics found in Experiment 1. If the deficit was caused by a general inability to use cue information we expected the same pattern of results with central-cognitive cues. By contrast, if the impairment was due to a specific processing deficit of peripheral information, we expected that by using central cues it would disappear, and the performance of dyslexic children would be comparable to that of normal readers. 


\section{Materials and Methods}

\section{Subjects}

Subjects were the same as in Experiment 1.

\section{Apparatus and Procedure}

Experimental conditions, stimuli, total number of trials and the number of each type of trial were the same as in Experiment 1. On valid and invalid trials the cue was a unidirectional arrow presented centrally (above the fixation point), pointing to the right or to the left side. On neutral trials the cue was a central bi-directional arrow pointing to both sides. We employed two different SOAs, 504 and $1000 \mathrm{~ms}$.

\section{Results}

Mean correct RTs were entered in a four-way repeated measure ANOVA, in which there was one between-subject factor, group (dyslexic children, normally reading children and adults), and three within-subject factors, type of trial (valid, invalid and neutral), SOA (504 and $1000 \mathrm{~ms}$ ) and stimulus position (right and left).

The group main effect was significant, $F(2,27)=5.7, p<0.01$; RTs of dyslexics $(508 \mathrm{~ms})$ were slower than those of normal readers (449 $\mathrm{ms}$ ) while RTs of adults were the fastest $(390 \mathrm{~ms})$. The main effect of type of trial was significant, $\mathrm{F}(2,54)=41.97, \mathrm{p}<0.001$; RTs were faster in valid trials $(416 \mathrm{~ms})$ and slower in invalid ones $(483 \mathrm{~ms})$ as compared with those of neutral trials (448 ms). The stimulus position was also significant, $F(1,27)=11.74, p<$ 0.01 ; RTs were faster when the stimulus appeared on the right side (443 ms) than on the left side (455 ms).

The stimulus position $\times$ SOA interaction was significant, $F(1,27)=5.15, p$ $<0.04$; RTs at the 1000-ms SOA were the same on both sides (443 ms each), whereas RTs at the 504-ms SOA were faster on the right side (443 ms) than on the left side $(464 \mathrm{~ms})$. The type of trial $\times$ group interaction was not significant, $\mathrm{F}(4,54)=0.17, \mathrm{p}=0.96$, which shows that voluntary orienting of attention did not differ across the three groups. Figure 2 shows that RTs of both normal readers $(\mathrm{A})$ and dyslexics $(\mathrm{B})$ were faster in valid trials and slower in invalid ones as compared with neutral trials.

\section{Discussion}

The main result of the present experiment is that dyslexics, as well as normally reading children and adults, showed both benefits and costs when the cue provided the correct or incorrect information, respectively. Although they were generally slower than normally reading children and adults, they were able to voluntarily direct attention according to the information suggested by the cue properly. On the basis of this finding we can reasonably rule out the hypothesis that dyslexics show a general inability to use the spatial information provided by the cue, that is to say, a general attentional disorder. By contrast, the present results provide evidence in favor of a specific automatic orienting deficit 


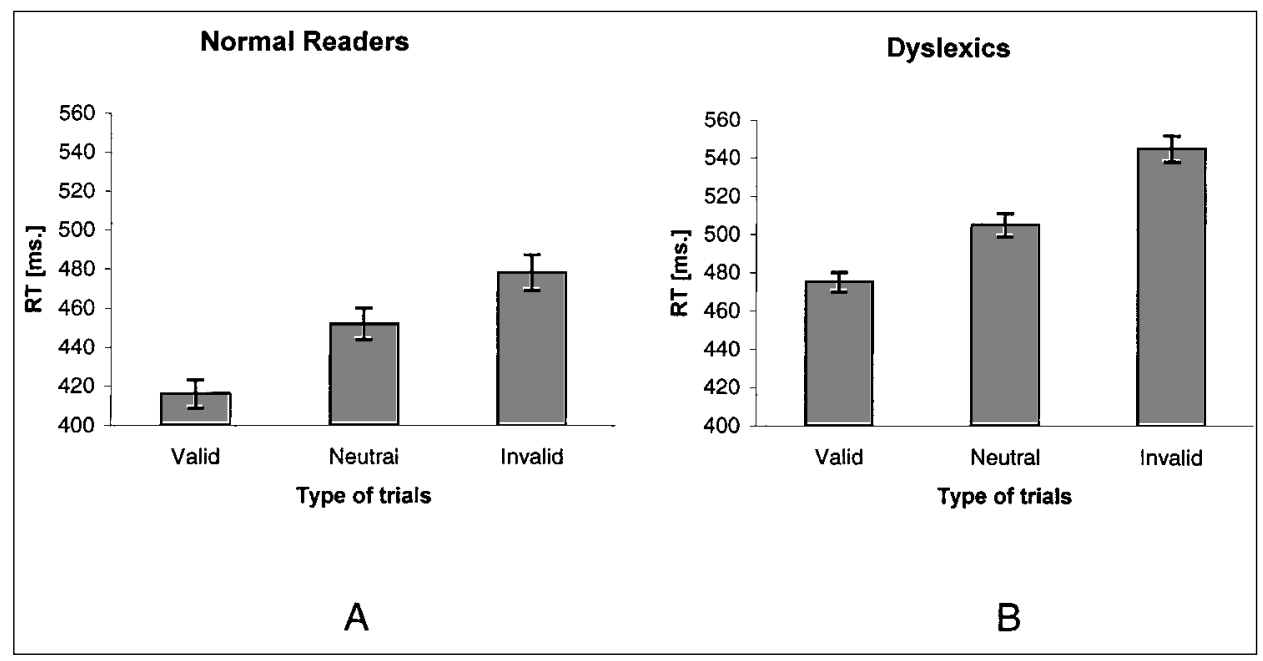

Fig. 2 - Mean reaction time (RT) as a function of validity and group of the central cue in Experiment 2 showing that the effect is significant for normal readers and dyslexics.

(Experiment 1), probably due to a dysfunction of the mechanism subserving the processing of peripheral transient signals (Breitmayer and Ganz, 1976).

However, an alternative account should be considered. In fact it should be noted that, beside the type of cue used (exogenous vs. endogenous), Experiments 1 and 2 differed also in the SOAs. So it can be argued that with longer SOAs (500 and $1000 \mathrm{~ms}$ ) dyslexic children are able to orient attention efficiently, and therefore, that the difference discriminant between the two Experiments is the speed at which attention is moved in the visual field.

Results of the present experiment are in accordance with those from a study of Jonkman, Licht, Bakker et al. (1992), in which the dyslexics' orienting mechanisms were addressed with a voluntary orienting paradigm. The authors found that normal readers responded faster and more accurately than dyslexics, but, very importantly, both groups showed faster responses when the cue provided the correct information than when it indicated an incorrect location. Surprisingly, however, the authors also found that RTs on neutral trials were slower than RTs on invalid trials. The authors interpreted this finding assuming that the ability to orient the attentional focus might have been affected by a developmental factor. In other words, they hypothesized that attentional control was still developing in children, and this affected their performances. However, the present study showed that voluntary orienting in the three groups exhibited the same RT pattern, that is, faster RTs on valid trials than on invalid ones, and intermediate RTs values on neutral cues. Consequently, it seems unlikely that the results of Jonkman et al. (1992) were affected by a developmental factor as the authors supposed. It is more likely that neutral trials showed the fastest RTs because of the type of neutral cue used. In fact, it is worth noting that in the study by Jonkman et al. (1992) the neutral cue was a circle presented in the center of the screen. This may have drawn attention to the center, thus affecting the distribution of attention across left and right visual fields. By contrast, in the 
present experiment the neutral cue consisted of a bi-directional arrow, which elicited a clear benefits-costs pattern (Posner, 1980).

\section{EXPERIMENT 3}

The deficit of automatic orienting shown by dyslexics may be explained in terms of three assumptions which are not mutually exclusive: (1) a deficit of the transient or magnocellular (M) pathway, as already discussed in Experiment 1, and/or (2) a reduced speed in the elementary operation of moving of attention, and/or (3) a difficulty to control the focus of attention correlated with a preference for a distributed attention modality, which would be peculiar to developmental dyslexia (Williams and Bologna, 1985; Geiger and Lettvin, 1987). Therefore, the purpose of this third experiment was to study some temporal aspects of attentional focusing in dyslexics and normally reading children.

As already mentioned, focusing is supposed to be sequential and independent of orienting (Benso et al., 1998; Castiello and Umiltà, 1990; Stoffer, 1991; Stoffer and Umiltà, 1997; Turatto et al., 1999). Focusing is activated upon orienting of attention towards an object in the visual field. Basically, focusing consists in adapting the spatial width of attentional resources to the size of the observed object. There is an inverse relation between focus size and processing efficiency, so that the smaller the focus size, the more concentrated inside its border are attentional resources, and the higher the speed of processing (e.g., Egeth, 1977; Eriksen and Yeh, 1985; Eriksen and St. James 1986; LaBerge, 1983).

In the present experiment, a pre-cue was used to orient subjects' gaze to the precise point of the visual field where the cue would appear. Therefore, orienting was performed in advance, and subjects had only to adjust the extent of their attentional focus to the cue size.

\section{Materials and Methods}

\section{Subjects}

Subjects were the same twenty children as in Experiments 1 and 2.

\section{Apparatus and Procedure}

The apparatus was the same as in previous experiments. The pre-cue was a green dot $\left(0.5^{\circ}\right.$ of visual angle), whereas the cues were two white circles of $2.5^{\circ}$ (small cue) and $7.5^{\circ}$ (large cue). The target was a white dot $\left(0.5^{\circ}\right)$ which was displayed, after a variable SOA ( 99 and $504 \mathrm{~ms}$, randomly presented), in the center of the cue. Stimuli luminance was 24 $\mathrm{cd} / \mathrm{m}^{2}$.

On each trial the pre-cue was flashed at the center of the screen for $238 \mathrm{~ms}$ accompanied by a $1000-\mathrm{Hz}$ tone. Then, the pre-cue was turned off and after a 136-ms interval the cue appeared on the screen center. After the SOA the imperative stimulus was shown for 99 ms. Upon detection of the target subjects had to press the spacebar on a computer keyboard, and RTs were recorded. The maximum time allowed for responding was $1 \mathrm{sec}$. During catch trials, which were intermingled with normal trials, subjects were not supposed to respond. 
The experimental session consisted of 152 trials, divided into two blocks of 76 trials each, and distributed as follows: 30 trials with the small cue (15 for each SOA), 30 with the large cue (15 for each SOA), and 16 catch trials (about $20 \%$ of the total trials).

\section{Results}

Mean correct RTs were entered in a three-way ANOVA, in which the between-subject factor was group (dyslexic children and normally reading children), while the two within-subject factors were cue size $\left(2.5^{\circ}\right.$ and $\left.7.5^{\circ}\right)$ and SOA (99 and $504 \mathrm{~ms}$ ).

The main effect of cue size was significant, $F(1,18)=14.62, p<0.02$. RTs were faster in the small cue condition $(412 \mathrm{~ms})$ than in the large cue condition (431 ms). Also, the main effect of SOA was significant, F $(1,18)=56.77$, p < 0.001 , indicating that the time interval between the cue and the target caused a warning effect that speeded RTs at the longest SOA $(99-\mathrm{ms}$ SOA $=457 \mathrm{~ms}$; 504-ms SOA = $385 \mathrm{~ms}$ ).

The group $\times$ cue size $\times$ SOA interaction was significant, $F(1,18)=4.45, p$ $<0.05$. Data were further analyzed by means of Newman-Keuls post-hoc tests. Results revealed a difference between normal readers and dyslexics in the ability to control the focus of attention as a function of SOA (Figure 3). Normal readers (see Figure 3A) showed a significant difference in RTs between large cue and small cue both at the 99-ms SOA (difference $24 \mathrm{~ms}, \mathrm{p}<0.05$ ), and at the 504ms SOA (difference $35 \mathrm{~ms}, \mathrm{p}<0.01$ ). By contrast, dyslexics (see Figure 3B) showed a significant difference in RTs between small and large cues at the 99ms SOA (difference $22 \mathrm{~ms}, \mathrm{p}<0.05$ ), but not at the 504-ms SOA.

\section{Discussion}

As previously discussed, a significant difference in RTs between large and small cues (cue-size effect) is supposed to index an active focusing process (e.g., Benso et al., 1998; Castiello and Umiltà, 1990; Turatto et al., 1999). Normally reading children exhibited the cue-size effect both at the 99- and 504-ms SOAs, thus confirming the results obtained by Benso et al. (1998) with adult subjects. By contrast, dyslexic children showed the cue-size effect at the shortest SOA only. In other words, in comparison with normal readers, dyslexics were able to exert an active focusing control only for a shorter period of time. Probably, at the longest SOA (504 ms) dyslexics no longer sustained attention, which may have led to an inefficient visual processing. This deficit could help explain the excessive slowness, errors and difficulties experienced by dyslexic children during reading. It is assumed that dyslexics, after a short period of time in which they focus on the target, shifted to a distributed modality of attention and a less efficient visual processing.

\section{GENERAL Discussion}

It is widely accepted that one of the major causes of reading disorders is the disability of children to distinguish between the phonemic sequences of sounds 


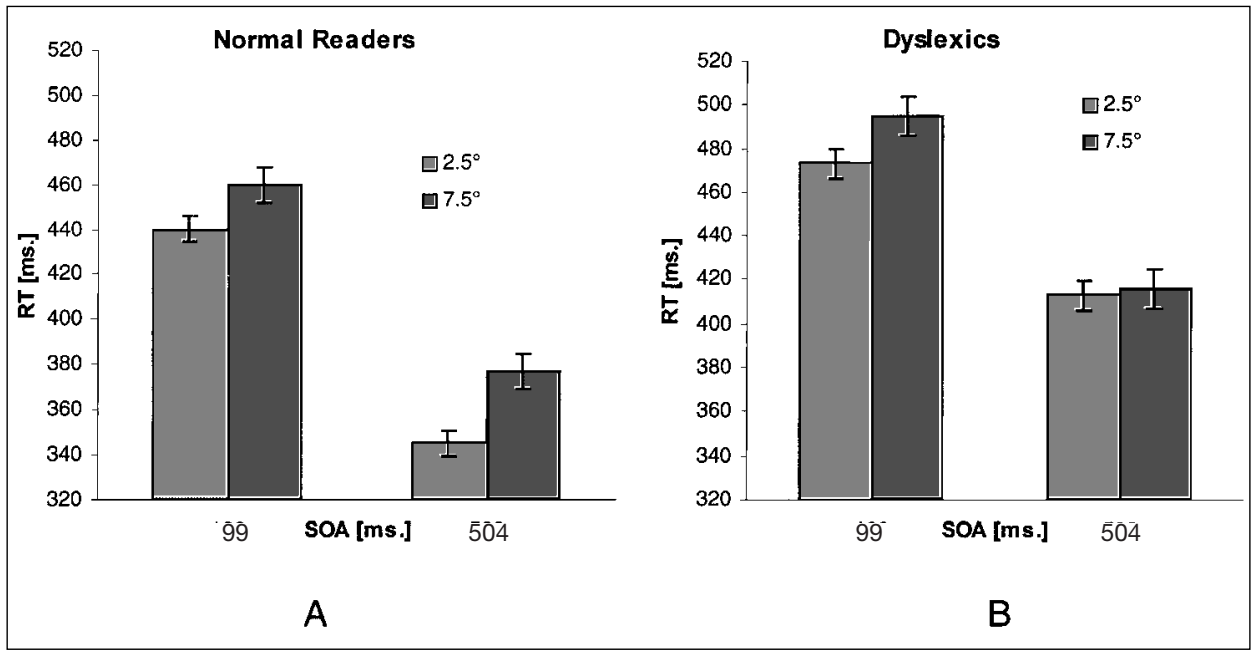

Fig. 3 - Mean reaction time $(R T)$ as a function of SOA, cue size and group in Experiment 3 showing that normal readers are capable of attentive focusing with 99-ms and 504-ms SOAs in contrast to dyslexics who are able to focus only at 99-ms SOA.

that comprise a word. In fact, disabled-reading or dyslexic children are significantly worse than normally reading children at discriminating phonemes (Bradley and Bryant, 1983).

However, reading also requires an accurate visual analysis allowing for a precise decoding of the written words. This is usually accomplished by shifting attention from a distributed to a more focused modality, which is also useful for minimizing the effect of laterally distracting information (LaBerge and Brown, 1989; LaBerge, Brown, Carter et al., 1991). It follows that the ability to orient the focus of attention as well as the ability to control its size are cognitive processes that are assumed to be deeply involved in reading (Morris and Rayner, 1991). Therefore, the question of the causal role of visual perceptual disorders in dyslexia (letters of a word in wrong or inverted position, words that are distorted or moving or overlapping) still remains open.

There is much evidence suggesting that the information encoded by the magnocellular visual pathway is crucial for the spatial attention processing (Johnson and Dark, 1986; LaBerge and Brown, 1989). It has been assumed that a dysfunction in the transient system might play a role in the occurrence of reading disorders (Stein and Walsh, 1997). Accordingly, several studies have reported the presence of attentional deficits associated with dyslexia (Williams and Bologna, 1985; Brannan and Williams, 1987; Geiger and Lettvin, 1987; Geiger et al., 1994; Rayner et al., 1989).

Hence, the aim of the present research was to investigate, in a more accurate manner, and using a simple detection task, whether dyslexia is associated with an impairment of both orienting and focusing of attention.

The main findings of the present study revealed that dyslexics were generally slower than normal readers and, specifically, that they were unable to shift attention automatically in response to a peripheral visual cue (Experiment 1), as 
already claimed by Brannan and Williams (1987). However, since the results of Experiment 2 showed that dyslexics were capable to use information provided by a central cue at longer SOAs, it seems reasonable to conclude that the deficit of the automatic orienting mechanism could be due to: 1) a selective impairment of the ability to process peripheral visual onset stimuli, and/or 2) a reduced speed in the elementary operation of moving of attention. A deficit of automatic orienting of attention could hamper the exact planning of ocular movements (saccades) which are crucial for correct and fast decoding during reading and which are known to be altered in children with dyslexia (Morris and Rayner, 1991).

In addition, as far as focusing of attention is concerned, dyslexics showed a limited control of the focus size over time. Impaired focusing in children with learning and reading disabilities has also been reported by Sharma et al. (1991) and Williams and Bologna (1985), respectively. Normal reading requires that each word is foveally viewed in order to achieve the highest spatial resolution analysis of the stimulus. However, attention is likely to remain focused on the word for as long as it is necessary in order to perform an efficient visual processing. Experiment 3 results revealed that dyslexic children were able to sustain focused attention for less time than normal readers, which might have affected detailed visual processing. Yet, the limited time during which focusing took place might be related to dyslexics' difficulty in suppressing the information flanking the observed word during reading (Geiger and Lettvin, 1987; Rayner et al., 1989; Geiger et al., 1994).

Finally, the simple detection task employed in all three experiments revealed deficits that may at least partially affect the early stages of the visual information processing. We could go as far as to suggest that they might even influence higher levels of processing that are assumed to be determinants in dyslexia.

In conclusion, it is suggested that the deficit of automatic orienting of attention (Experiment 1) could affect the planning of ocular movements, which are crucial for reading. Moreover, the incapability to sustain focusing of attention (Experiment 3) might be linked to disorder of ocular fixation, during which visual information is retrieved in order to decode the written text, which could affect reading, by not allowing exclusion of laterally-distracting information.

\section{REFERENCES}

Ackerman, P.T., Dykman, R.A., and Gardner, M.T. ADD students with and without dyslexia differ in sensitivity to rhyme and alliteration. Journal of Learning Disabilities, 23: 279-283, 1990.

August, G.J., and Garfinkel, B.D. Comorbility of ADHD and reading disability among clinically referred children. Journal of Abnormal Psychology, 18: 29-45, 1990.

Benso, F., Turatto, M., Mascetti, G.G., and Umiltà, C. The time course of attentional focussing. European Journal of Cognitive Psychology, 10: 373-388, 1998.

Bradley, L., and Bryant, P. Categorizing sounds and learning to read: A causal connection. Nature, 301: 419-421, 1983.

Brannan, J., and Williams, M. Allocation of visual attention in good and poor readers. Perception and Psychophisics, 41: 23-28, 1987.

BREITMEYER, B.G., and GANZ, L. Implications of sustained and transient channels for theories of visual pattern masking, saccadic suppression, and information processing. Psychological Review, 83: 1-36, 1976. 
CAsco, C., and PrunetTi, E. Visual search in good and poor readers: Effects with single and combined features targets. Perceptual and Motor Skills, 82: 1155-1167, 1996.

Casco, C., Tressoldi, P., and Dellantonio, A. Visual selective attention and reading efficiency are related in children. Cortex, 34: 531-546, 1998.

Castiello, U., and Umiltà, C. Size of the attentional focus and efficiency of processing. Acta Psychologica, 73: 195-209, 1990.

CoRnoldi, C., and Colpo, M. La verifica oggettiva della lettura. Firenze: Organizzazioni Speciali, 1981.

Egeth, H. Attention and preattention. In G.H. Bower (Ed.), The Psychology of Learning and Motivation, 1977, 11, pp. 277-320.

Epstein, J.N., Conners, C.K., Erhardt, D., Marsh, J.S., and Swanson, J.M. Asymmetrical hemispheric control of visual-spatial attention in adults with attention deficit hyperactivity disorder. Neuropsychology, 11: 467-473, 1997.

ERIKSEN, C.W., and ST. James, J.D. Visual attention within and around the field of focal attention: A zoom lens model. Perception and Psychophysics, 40: 225-240, 1986.

ERIKSEN, C.W., and YEH, Y. Allocation of attention in the visual field. Journal of Experimental Psychology: Human Perception and Performance, 5: 583-595, 1985.

Geiger, G., and LetTvin, J.Y. Peripheral vision in persons with dyslexia. New England Journal of Medicine, 316: 1238-1243, 1987.

Geiger, G., Lettvin, J.Y., and FAHLE, M. Dyslexic children learn a new visual strategy for reading: A controlled experiment. Vision Research, 34: 1223-1233, 1994.

Hinshelwood, J. Congenital Word Blindness. Chicago: Medical Book, 1917.

Hoffman, K.P., Stone, J., and Sherman, S.M. Relay of receptive-field properties in dorsal lateral geniculate nucleus of the cat. Journal of Neurophysiology, 35: 518-531, 1972.

Inhoff, A.W., Pollatsek, A., Posner, M.I., and Rayner, K. Covert attention and eye movements during reading. Quarterly Journal of Experimental Psychology, 41: 63-89, 1989.

Johnson, J. Visual attention and the control of eye movements in early infancy. In C. Umiltà and M. Moscovitch (Eds.), Attention and Performance. Cambridge: MIT Press, 1994, XV, pp. 291-310.

Johnston, W.A., and Dark, V.J. Selective attention. Annual Review of Psychology, 37: 43-75, 1986.

JoNIDES, J. Voluntary versus automatic control over the mind's eye's movement. In J.B. Long and A.D. Baddeley (Eds.), Attention and Performance. Hillsdale, N.J.: Erlbaum, 1981, IX, pp.187-203.

Jonkman, I., Licht, R., BAKKeR, D.J., and VAN DEN BroeK-SAndmann, T.M. Shifting of attention in subtyped dyslexics children: An event-related potential study. Developmental Neuropsychology, 8: 243-259, 1992.

JORN, A.F. Specific reading retardation and working memory: A review. British Journal of Psychology, 74: 311-342, 1983.

LaBerge, D. Spatial extent of attention to letters and words. Journal of Experimental Psychology: Human Perception and Performance, 9: 371-379, 1983.

LaBerge, D., and Brown, V. Theory of attentional operations in shape identification. Psychological Review, 96: 101-124, 1989.

LaBerge, D., Brown, V., Carter, M., Bash, D., and Hartley, A. Reducing the effects of adjacent distractors by narrowing attention. Journal of Experimental Psychology: Perception and Performance, 17: 65-76, 1991.

Liberman, I.Y., MANn, U.S., and Shankweiler, D. Children's memory for recurring linguistic and non linguistic material in relation to reading ability. Cortex, 18: 367-375, 1982.

Livingstone, M.S., Rosen, G., Drislane, F., and Galaburda, A. Physiological and anatomical evidence for a magnocellular defect in developmental dyslexia. Proceedings of the National Academy of Science, 88: 7943-7947, 1991.

Lovegrove, W.J., Martin, F., and Slaghuis, W. Reading disability: Spatial frequency specific deficits in visual information store. Cognitive Neuropsychology, 3: 225-267, 1982.

Marsh, G., Freidman, M., and Welsh, V. A cognitive development theory of reading acquisition. In G.E. Mackinnon and T.G. Waller (Eds.), Reading Research: Advances in Theory and Practice. New York: Academic Press, 1981, pp. 87-102.

MORRIS, R.K., and RAYNER, K. Eye movements in skilled reading: Implications for developmental dyslexia. In J.F. Stein (Ed.), Vision and Visual Dyslexia. London: MacMillan Press, 1991, pp. 233242.

Muller, H.J., and RabBitT, P.M.A. Reflexive and voluntary orienting of visual attention: Time course of activation and resistance to interruption. Journal of Experimental Psychology: Human Perception and Performance, 15: 315-330, 1989.

OrganizzaZione Mondiale DELla SANità. ICD-10 Classificazione delle Sindromi e dei Disturbi Psichici e Comportamentali. Milano: Masson, 1996.

Orton, S.T. Reading Writing and Speech Problems in Children. New York: Norton, 1937.

Posner, M.I. Orienting of attention. Quarterly Journal of Experimental Psychology, 32A: 2-25, 1980.

Posner, M.I., Cohen, Y., and Rafal, R.D. Neural systems control of spatial orienting. Proceedings of the Royal Society of London B, 298: 187-198, 1982. 
Posner, M.I., Cohen, Y., ChoAte, L.S., Hockey, R., and MaYlor, E. Sustained concentration: Passive filtering or active orienting. In S. Kornblum and J. Requin (Eds.), Preparatory States and Processes. Hillsdale, NJ: Erlbaum, 1984, pp. 49-65.

Posner, M.I., and Petersen, S.E. The attentional system of the human brain. Annual Review of Neuroscience, 13: 25-42, 1990.

Posner, M.I., Snyder, C.R.R., and Davidson, B.J. Attention and the detection of signals. Journal of Experimental Psychology: General, 109: 160-174, 1980.

Posner, M.I., Walker, J.A., Friedrich, A.J., and RAFAL, R.D. Effect of parietal lobe injury on cover orienting of visual attention. Journal of Neuroscience, 4: 1863-1874, 1984.

RAFAL, R.D., and Posner, M.I. Deficit in human spatial attention following thalamic lesions. Proceedings of the National Academy of Sciences, 84: 7349-7353, 1987

Rayner, K., Murphy, L.A., Henderson, J.M., and Pollatsek, A. Selective attentional dyslexia. Cognitive Neuropsychology, 6: 357-378, 1989.

Rosen, A.C., Rao, S.M., Caffarra, P., Scaglioni, A., Bobholz, J.A., Woodley, S.J., Hammeke, T.A., Cunningham, J.M., Prieto, T.E., and Binden, J.R. Neural basis of endogenous and exogenous spatial orienting: A functional MRI study. Journal of Cognitive Neuroscience, 11: 135-152, 1999.

Rozin, P., and Gleitman, L. The structure and acquisition of reading II. The reading process and the acquisition of the alphabetic principle. In A.S. Reber and D.L. Scarborough (Eds.), Toward a Psychology of Reading. Hillsdale N.J.: Erlbaum, 1977, pp. 49-65.

Ruddock, K.H. Visual search and dyslexia. In J.F. Stein (Ed.), Vision and Visual Dyslexia. London: MacMillan Press, 1991, Vol. 13, pp. 58-79.

Sharma, V., Halperin, J.H., Newcorn, J.N., and Wolf, N.E. The dimension of focussed attention: Relationship to behavior and cognitive functioning in children. Perceptual and Motor Skills, 72: 787-793, 1991.

Shepar, M., Findlay, J.M., and Hockey, R.J. The relationship between eye movements and spatial attention. The Quarterly Journal of Experimental Psychology, 38: 475-491, 1986.

Stein, J., and WALSH, V. To see but not to read; the magnocellular theory of dyslexia. Trends in Neurosciences, 20: 147-152, 1997.

Stoffer, T.H. Attentional focussing and spatial stimulus-response compatibility. Psychological Research, 53: 127-135, 1991.

StofFer, T.H., and UmiLtÀ, C.A. Spatial stimulus coding and the focus of attention in S-R compatibility and the Simon effect. In B. Hommel and W. Prinz (Eds.), Theoretical Issues in Stimulus-Response Compatibility. Amsterdam: Elsevier, 1997, pp. 181-208.

Turatto, M., Benso, F., Facoetti, A., Galfano, G., Mascetti, G.G., and Umiltà, C. Automatic and voluntary focusing of attention. Perception and Psychophysics, 1999 (in press).

VAN DER HeIJDEN, A.C.H. Selective Attention in Vision. London: Routledge, 1992.

WARner, C.B., JuOLA, J.F., and Koshino, H. Voluntary allocation versus automatic capture of visual attention. Perception and Psychophysics, 48: 243-251, 1990.

WeChSLER, D. Scala di Intelligenza Wechsler per Bambini - Riveduta. Firenze: Organizzazioni Speciali, 1986.

Williams, M.C., and Bologna, N.B. Perceptual grouping in good and poor readers. Perception and Psychophysics, 38: 367-374, 1985.

Williams, M.C., Brannan, J.R., and LatiRgue, E.K. Visual search in good and poor readers. Clinical Vision Science, 1: 367-371, 1987.

Gian Gastone Mascetti, Dipartimento di Psicologia Generale, Università di Padova, Via Venezia 8, 35131 Padova, Italy. E-mail: mascetti@psico.unipd.it

(Received 17 March 1999; accepted 11 october 1999) 